\title{
Diamines Can Initiate New Particle Formation in the Atmosphere
}

\author{
Elm, Jonas
}

2017-08-17

Elm , J , Passananti , M , Kurten , T \& Vehkamäki , H 2017 , ' Diamines Can Initiate New Particle Formation in the Atmosphere ' , Journal of Physical Chemistry A, vol. 121 , no. 32 , pp. 6155-6164 . https://doi.org/10.1021/acs.jpca.7b05658

http://hdl.handle.net/10138/299838

https://doi.org/10.1021/acs.jpca.7b05658

unspecified

acceptedVersion

Downloaded from Helda, University of Helsinki institutional repository.

This is an electronic reprint of the original article.

This reprint may differ from the original in pagination and typographic detail.

Please cite the original version. 


\section{Diamines Can Initiate New Particle Formation in the Atmosphere}

Jonas Elm, ${ }^{*} \dagger$ Monica Passananti, $\ddagger$ Theo Kurtén, $\uparrow$ and Hanna Vehkamäki $\ddagger$

Department of Chemistry, Aarhus University, Denmark, Department of Physics, University

of Helsinki, Finland, and Department of Chemistry, University of Helsinki, Finland

E-mail: jelm@chem.au.dk

${ }^{*}$ To whom correspondence should be addressed

${ }^{\dagger}$ Aarhus University

${ }^{\ddagger}$ University of Helsinki

IUniversity of Helsinki 


\begin{abstract}
Recent experimental evidence suggests that diamines can enhance atmospheric new particle formation more efficiently compared to monoamines such as dimethylamine. Here we investigate the molecular interactions between sulfuric acid (sa) and the diamine putrescine (put) using computational methods. The molecular structure of up to four sulfuric acid molecules and up to four putrescine molecules were obtained at the $\omega \mathrm{B} 97 \mathrm{X}-\mathrm{D} / 6-31++\mathrm{G}(\mathrm{d}, \mathrm{p})$ level of theory. We utilized a domain local pair natural orbital coupled cluster method - DLPNO-CCSD(T)/aug-cc-pVTZ - to obtain highly accurate binding energies of the clusters. We find that the $(\mathrm{sa})_{1-4}(\mathrm{put})_{1-4}$ clusters show more ionic character than clusters consisting of sulfuric acid and dimethylamine (dma) by readily forming several sulfate ions in the cluster. To estimate the stability of the clusters we calculate the evaporation rates and compare them to ESIAPi-TOF measurements. Using the atmospheric cluster dynamics code (ACDC) we simulate and compare the new particle formation rates between the $(\mathrm{sa})_{1-4}(\mathrm{put})_{1-4}$ and $(\mathrm{sa})_{1-4}(\mathrm{dma})_{1-4}$ cluster systems. We find that putrescine significantly enhances the formation of new particles compared to dimethylamine. Our findings suggest that a large range of amines with different basicity is capable of explaining various regions of the observed new particle formation events. These results indicate that diamines, or related compounds with high basicity, might be important species in forming the initial cluster with sulfuric acid and subsequently more abundant amines with lower basicity can assist in the new particle formation process by attaching to the sulfuric acid - diamine nucleus.
\end{abstract}




\section{Introduction}

The interaction between aerosol particles and clouds remains the least understood phenomenon in global climate modelling. ${ }^{1}$ Formation of new particles in the atmosphere is estimated to account for $\sim 50 \%$ of cloud condensation nuclei, ${ }^{2}$ which directly affect the brightness and lifetime of clouds. Sulfuric acid is believed to be a common precursor enforcing new particle formation in many inland environments, ${ }^{3}$ but another stabilizing vapour is required to explain new particle formation events observed in the atmosphere. ${ }^{4-6}$ Atmospheric bases are key species for stabilizing sulfuric acid clusters mediated via proton transfer reactions. However, the most abundant base in the atmosphere - ammonia - cannot explain observed new particle formation events. ${ }^{5}$ Experiments, simulating realistic atmospheric conditions, performed at the CLOUD chamber at CERN showed that mixing ratios as low as 3 pptv of dimethylamine can enhance new particle formation rates more than three orders of magnitude compared to 250 pptv of ammonia. ${ }^{7}$ Based on CI-APi-TOF experiments it has been suggested that even some of the smallest clusters consisting of only two sulfuric acid molecules and 1-2 dimethylamine molecules can be considered stable as they are not susceptible to reevaporation. ${ }^{8}$ This illustrates that the basicity can to some extent be more important than the atmospheric abundance of the base in the context of forming new particles. ${ }^{9-11}$

More than 150 amines have been detected in the atmosphere, ${ }^{12}$ but it is still unknown whether amine mixing ratios at the pptv level are present in pristine environments such as boreal forests. ${ }^{13}$ However, recent evidence suggests that amine concentrations can be linked directly to vegetation, litterfall and soil activity ${ }^{14}$ and generally is higher in boreal forest environments compared to urban air. ${ }^{15}$ Amine concentrations have been shown to be associated with fungal hyphae, and especially fungal groups belonging to decay and ectomy-

corrhizal fungi produced high concentrations of amines. ${ }^{16}$ These types of fungal groups have also been shown to produce diamines, such as putrescine, cadaverine, spermidine and spermine, during a symbiotic process of stimulating plant root growth in for instance Scots pine trees. ${ }^{17,18}$ This could elevate the concentration of these diamines in the soil and potentially 
be a source of diamine emission to the atmosphere. Recent measurements at three different sites indicated that diamines (putrescine and cadaverine) are omnipresent in the ambient atmosphere and can reach or even exceed the concentration of monoamines, with measured mixing ratios as high as tens of pptv. ${ }^{19}$ Flow tube experiments have demonstrated that diamines can produce 10 times more particles than dimethylamine and 100 times more than methylamine at mixing ratios of 1 pptv. ${ }^{19}$ Using computational methods we recently showed that diamines bind significantly stronger to sulfuric acid compared to monoamines such as dimethylamine. ${ }^{11}$ However, very little is known about the atmospheric fate of diamines and the exact mechanism on how they influence new particle formation.

In this paper we investigate the molecular interactions between sulfuric acid and the diamine putrescine $\left(\mathrm{H}_{2} \mathrm{~N}\left(\mathrm{CH}_{2}\right)_{4} \mathrm{NH}_{2}\right)$ using computational methods. We extend the currently available thermochemical data by considering large molecular clusters up to four acids and four bases. Using the Atmospheric Cluster Dynamics Code (ACDC) we present a mechanism for the cluster growth and compare the results to the sulfuric acid - dimethylamine system.

\section{Methods}

\subsection{Compuational Details}

All geometry optimizations and vibrational frequency calculations, were performed with the Gaussian 09 program, revision B.01. ${ }^{20}$ We have employed the $\omega$ B97X-D ${ }^{21}$ functional for all optimizations and vibrational frequency calculations as it has shown superior performance compared to other common functionals in calculating binding energies of atmospheric clusters. $^{22,23}$ We utilized the $6-31++\mathrm{G}(\mathrm{d}, \mathrm{p})$ basis set as it has been shown to be a good compromise between accuracy and efficiency and does not yield significant errors compared to larger basis sets. ${ }^{24,25}$ As a comparison we have also calculated the formation free energies using the commonly utilized ${ }^{26-29}$ PW91/6-311++G(3df,3pd) level of theory (see the supporting information). 
Explicitly correlated coupled cluster calculations (CCSD(T)-F12a ${ }^{30-32} /$ VDZ-F12 ${ }^{33}$ ) were performed using Molpro $2012^{34}$ and domain based local pair natural orbital coupled cluster calculations - DLPNO-CCSD $(\mathrm{T})^{35,36}$ - were performed using ORCA 3.0.3. ${ }^{37}$

\section{$2.2 \quad$ Binding Free Energies}

We calculate the binding free energy of the clusters as the free energy of the cluster relative to its consisting monomers:

$$
\Delta G_{\text {bind }}=G_{\text {cluster }}-\sum G_{\text {monomer }}
$$

The binding free energy can be partitioned into a pure electronic contribution $\left(\Delta E_{\mathrm{bind}}\right)$ and a thermal contribution ( $\left.\Delta G_{\text {thermal }}\right)$ to the Gibbs free binding energy:

$$
\Delta G_{\text {bind }}=\Delta E_{\text {bind }}+\Delta G_{\text {thermal }}
$$

A practical approach is to employ DFT for obtaining the geometry and vibrational frequencies, i.e. the $\Delta G_{\text {thermal }}$ contribution, and then use a higher level of theory to obtain the

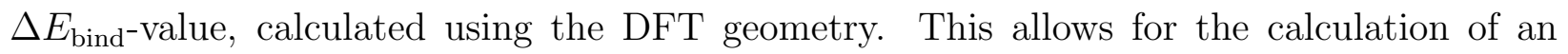
approximate $\Delta G_{\text {bind }}^{\mathrm{CCSD}(\mathrm{T})^{*}}$-value in the following manner:

$$
\Delta G_{\text {bind }}^{\mathrm{CCSD}(\mathrm{T})^{*}}=\Delta E_{\text {bind }}^{\mathrm{CCSD}(\mathrm{T})}+\Delta G_{\text {thermal }}^{\mathrm{DFT}}
$$

Based on benchmark calculations against a CCSD(T)-F12a/VDZ-F12 reference, we find that the most cost-efficient method for calculating the binding energy is the DLPNO$\operatorname{CCSD}(\mathrm{T})$ /aug-cc-pVTZ level of theory. For further analysis of the binding energy contribution, we refer to the supporting information section S3.

The harmonic oscillator approximation becomes a large source of errors when low vibrational frequencies are present in the cluster. Essentially these low frequency vibrations 
are not strictly vibrations, but corresponds to a collective pivotal movement of the cluster. To correct the vibrational entropies of low-lying frequencies we employ the quasi-harmonic approximation, ${ }^{38}$ where the contribution of low frequencies to the entropy is replaced by a corresponding rotational entropy. This allows for a better physical depiction of these vibrations. We have chosen a vibrational frequency cut-off value of $200 \mathrm{~cm}^{-1}$. The quasi-harmonic calculations were performed using the freely available Goodvibes.py script by Funes-Ardois and Paton. ${ }^{39}$ For more details on the performance of the quasi-harmonic approximation we refer to the supporting information section S4.

\subsection{Obtaining the Cluster Structures}

We study molecular cluster structures consisting of sulfuric acid (sa) and either dimethylamine (dma) or putrescine (put). The molecular structures of $(\mathrm{sa})_{1-4}(\mathrm{dma})_{1-4}$ have previously been reported in the literature by Loukonen et al. ${ }^{40}$ and Ortega et al. ${ }^{41}$ We have re-evaluated the cluster structures by including a new round of conformational sampling at the $\omega \mathrm{B} 97 \mathrm{X}-\mathrm{D} / 6-31++\mathrm{G}(\mathrm{d}, \mathrm{p})$ level of theory. Based on inspection of the favourable binding patterns of the existing cluster structures, we constructed 10 or more new cluster structures for each cluster configuration using chemical intuition. This led to the identification of several new lower lying free energy minima than previously reported as shown in the Supporting information.

To obtain the $(\mathrm{sa})_{1-4}(\mathrm{put})_{1-4}$ cluster structures, we used the previously available ${ }^{11}(\mathrm{sa})_{1-4}(\mathrm{put})_{1}$ clusters as a starting point. The larger cluster structures were sampled with a combination of our previously applied semi-empirically guided sampling technique ${ }^{42}$ and manual sampling using chemical intuition based on the previously identified favourable binding patterns.

\subsection{ACDC Simulations}

The steady state concentrations of the molecular clusters, were simulated using the Atmospheric Cluster Dynamics Code (ACDC). ${ }^{41,43,44}$ Supporting information contains details 
about the underlying equations in the ACDC simulations.

In laboratory experiments and measurements in the ambient atmosphere the formation rate of clusters with mobility diameter $1.7 \mathrm{~nm}\left(J_{1.7 \mathrm{~nm}}\right)$ is a usual measure for new particle formation. ${ }^{7,45,46}$ The clusters employed in our simulation includes up to four sulfuric acid molecules and four base molecules and the largest cluster studied measures $~ 1.5 \mathrm{~nm}$ in mobility diameter. In our simulation we will define a new "particle" as a cluster which has a low enough evaporation rate to assume that it will not evaporate in the atmosphere. Our simulated new particle formation rate is thereby the flux of clusters which leave the system and does not evaporate back into the system.

In all our simulations we use an additional loss term due to coagulation with larger particles. Loss due to coagulation was set to a constant value of $2.6 \cdot 10^{-3} \mathrm{~s}^{-1}$, which corresponds to typical values observed in boreal forest environments. ${ }^{47,48}$

\subsection{ESI-APi-TOF Measurements}

The experiments were carried out using an ElectroSpray Ionization Atmospheric Pressure interface Time-Of-Flight mass spectrometer (ESI-APi-TOF). Negatively charged clusters were introduced into an APi-TOF (Tofwerk) mass spectrometer by electrospray of a 100 $\mathrm{mM}$ sulfuric acid and $50 \mathrm{mM}$ base (putrescine or cadaverine) solution in a water/methanol $1 / 1 \mathrm{v} / \mathrm{v}$. The APi-TOF was operated in negative mode and the data were analysed using a Matlab based set of programs (tofTools) developed at the University of Helsinki, more details about the instrument are reported elsewhere. ${ }^{49}$

\section{Results and Discussion}

\subsection{Cluster Structures}

We have previously investigated clusters consisting of one to four sulfuric acid (sa) molecules and a single putrescine (put) molecule. ${ }^{11}$ We found that already the smallest (sa) ${ }_{1}$ (put) ${ }_{1}$ clus- 
ter exhibits a single proton transfer from sulfuric acid to putrescine. In the (sa) $)_{2-4}(\text { put })_{1}$ clusters a proton is transferred from a second sulfuric acid molecule to the putrescine molecule. Figure 1 presents the lowest Gibbs free energy (sa) ${ }_{1-4}(\text { put })_{1-4}$ cluster structures, obtained at the $\omega \mathrm{B} 97 \mathrm{X}-\mathrm{D} / 6-31++\mathrm{G}(\mathrm{d}, \mathrm{p})$ level of theory. The clusters consisting purely of bases (put) $)_{2-4}$ - can be seen in the supporting information. 


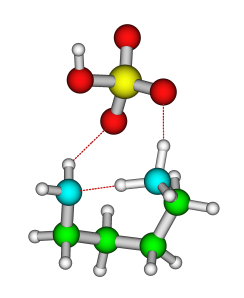

(sa) ${ }_{1}$ (put) 1

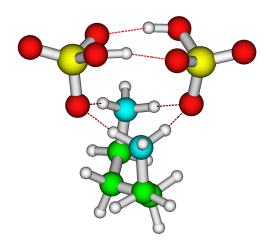

(sa) $)_{2}$ (put) 1
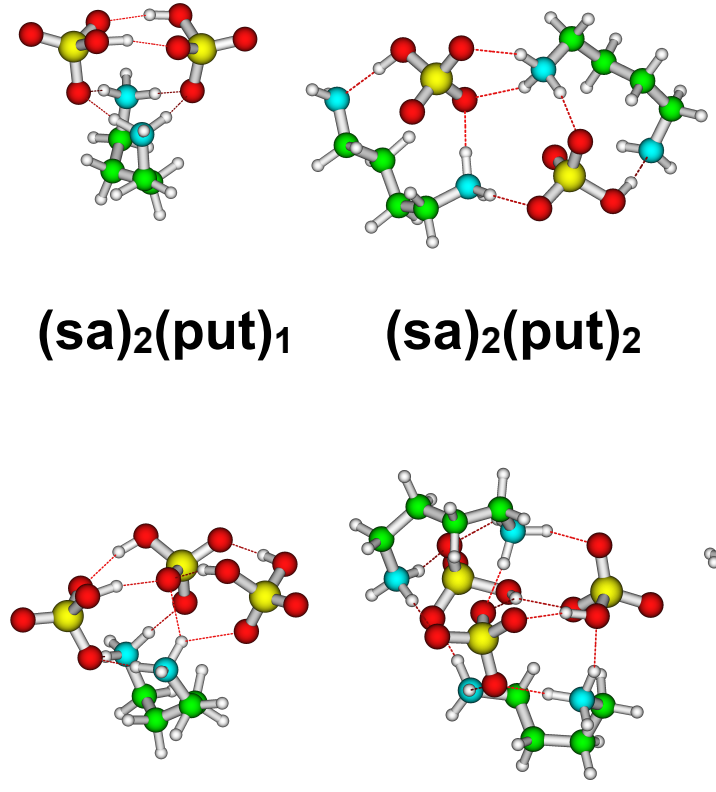

(sa) $)_{3}$ (put) 1

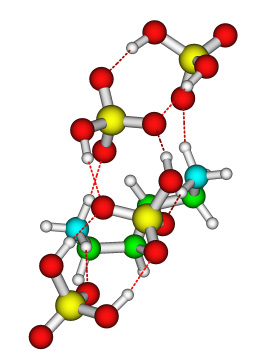

(sa) ${ }_{4}$ (put) 1

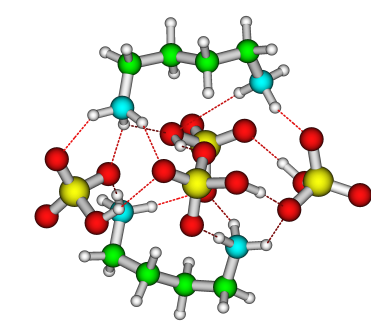

(sa) 4 (put) 2 (sa) $)_{2}$ put) 2

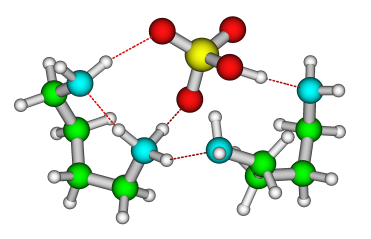

(sa) ${ }_{1}$ (put) 2

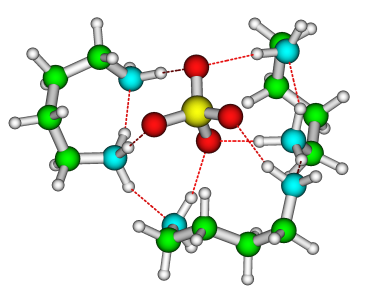

(sa) ${ }_{1}$ (put) $)_{3}$

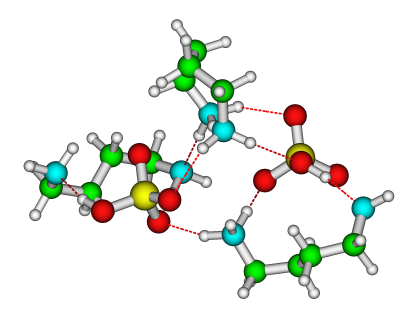

(sa) $)_{2}$ (put) 3

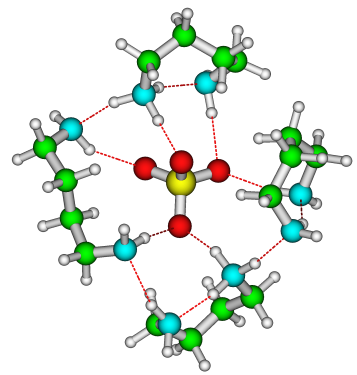

(sa) ${ }_{1}$ (put) ${ }_{4}$

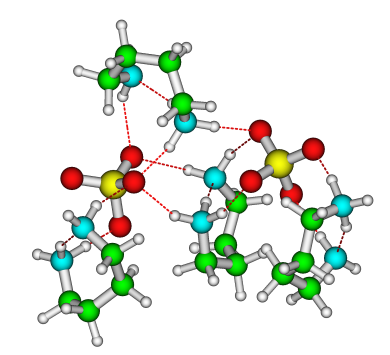

(sa) ${ }_{2}$ (put) 4
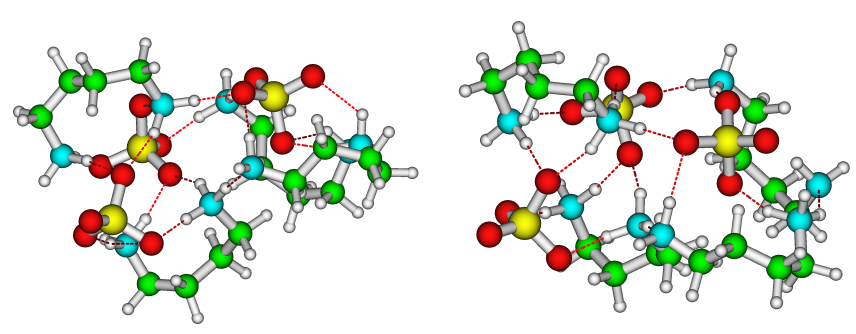

(sa) ${ }_{3}$ (put) ${ }_{3}$

$(\text { sa) })_{3}$ (put) ${ }_{4}$

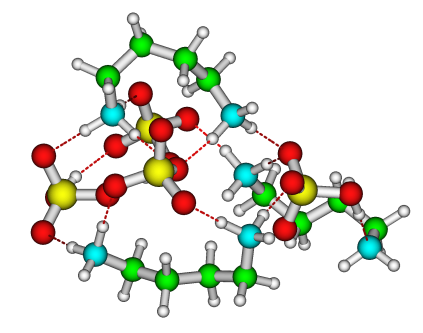

(sa) 4 (put) 3

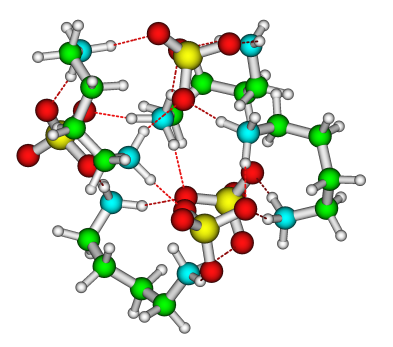

(sa) ${ }_{4}$ (put) ${ }_{4}$

Figure 1: Lowest Gibbs free energy structures of the $(\mathrm{sa})_{1-4}(\mathrm{put})_{1-4}$ clusters. The cluster structures were obtained at the $\omega \mathrm{B} 97 \mathrm{X}-\mathrm{D} / 6-31++\mathrm{G}(\mathrm{d}, \mathrm{p})$ level of theory. Green = carbon, blue $=$ nitrogen, yellow $=$ sulfur, red $=$ oxygen and white $=$ hydrogen . 
In general, a proton transfer from sulfuric acid to putrescine occurs in all the clusters. This proton transfer allows for the formed $-\mathrm{NH}_{3}{ }^{+}$group in the putrescine molecule to interact with the $-\mathrm{NH}_{2}$ group of either the same or other putrescine molecules. These secondary interactions greatly stabilize the clusters and are observed in most of the $(\mathrm{sa})_{1-4}$ (put) $)_{1-4}$ clusters. The secondary interactions form a large network consisting of both hydrogen bonded and ionic interactions in the clusters.

The (sa) $)_{1}$ (put) $)_{1-4}$ clusters form a ring of putrescine molecules around the sulfuric acid molecule, as they compete to interact with the sulfuric acid. A second proton transfer from sulfuric acid to a second putrescine molecule is observed in the $(\mathrm{sa})_{1}(\mathrm{put})_{3-4}$ clusters, resulting in the formation of a sulfate ion $\left(\mathrm{SO}_{4}{ }^{2-}\right)$. A sulfate ion was not observed to form in any clusters with only one putrescine molecule. Except for the $(\mathrm{sa})_{2}(\mathrm{put})_{3}$ cluster, sulfate ions form when three or four putrescine molecules are present in the cluster. In case of the $(\mathrm{sa})_{1-4}(\text { put })_{4}$ clusters all sulfuric acid molecules are completely deprotonated, and exclusively found as sulfate ions. Table 1 summarises the extent of proton transfers observed in the $(\mathrm{sa})_{1-4}(\mathrm{put})_{1-4}$ and $(\mathrm{sa})_{1-4}(\mathrm{dma})_{1-4}$ clusters. Each $*$ indicates that a sulfate ion is formed.

Table 1: Observed number of proton transfers in the $(\mathrm{sa})_{1-4}(\mathrm{put})_{1-4}$ and $(\mathrm{sa})_{1-4}(\mathrm{dma})_{1-4}$ clusters. Each asterisk $\left.*^{*}\right)$ indicates the formation of a sulfate ion in the cluster.

\begin{tabular}{ccccccccc}
\hline \hline Cluster & $(\mathrm{put})_{1}$ & $(\mathrm{put})_{2}$ & $(\mathrm{put})_{3}$ & $(\mathrm{put})_{4}$ & $(\mathrm{dma})_{1}$ & $(\mathrm{dma})_{2}$ & $(\mathrm{dma})_{3}$ & $(\mathrm{dma})_{4}$ \\
\hline \hline$(\mathrm{sa})_{1}$ & 1 & 1 & $2^{*}$ & $2^{*}$ & 1 & 1 & 1 & $2^{*}$ \\
$(\mathrm{sa})_{2}$ & 2 & 2 & 2 & $4^{* *}$ & 1 & 2 & $3^{*}$ & $3^{*}$ \\
$(\mathrm{sa})_{3}$ & 2 & $4^{*}$ & $4^{*}$ & $6^{* * *}$ & 1 & 2 & 3 & $4^{*}$ \\
$(\mathrm{sa})_{4}$ & 2 & 4 & $5^{*}$ & $8^{* * * *}$ & 1 & 2 & 3 & 4
\end{tabular}

The formation of several sulfate ions in sulfuric acid - base clusters has not previously been observed in electrically neutral clusters. In the sulfuric acid - dimethylamine system a sulfate ion is only formed in the $(\mathrm{sa})_{1}(\mathrm{dma})_{4},(\mathrm{sa})_{2}(\mathrm{dma})_{3-4}$ and $(\mathrm{sa})_{3}(\mathrm{dma})_{4}$ clusters: the sulfate ion is only formed when there is more dimethylamine than sulfuric acid molecules in the cluster, and at most these clusters contain a single sulfate ion. The amount of proton 
transfers in the $(\mathrm{sa})_{1-4}(\mathrm{dma})_{1-4}$ clusters cannot exceed the amount of dma molecules and hence a maximum of four protons can be transferred. However, as each putrescine molecule has two amino groups, it is capable of accepting two protons, which leads to a total of up to eight protons which can be transferred. The fact that sulfate ions are readily formed in the sulfuric acid - putrescine system can thus be attributed both to the higher basicity of putrescine compared to dimethylamine, and to the additional amino group acting as a proton acceptor in putrescine. Thus the $(\mathrm{sa})_{1-4}(\text { put })_{1-4}$ clusters are significantly more ionic than their $(\mathrm{sa})_{1-4}(\mathrm{dma})_{1-4}$ counterparts. The more ionic character of the $(\mathrm{sa})_{1-4}(\text { put })_{1-4}$ clusters is further corroborated by a higher dipole moment and polarizability compared to the $(\mathrm{sa})_{1-4}(\mathrm{dma})_{1-4}$ clusters (see supporting information).

\subsection{Cluster Free Energy Surfaces}

Having a more ionic character might stabilize the clusters. Based on mass balance relations we have calculated the formation free energy surfaces of the $(\mathrm{sa})_{1-4}(\mathrm{put})_{1-4}$ and $(\mathrm{sa})_{1-4}(\mathrm{dma})_{1-4}$ clusters at ambient trace gas concentrations (see Figure 2). The concentration of sulfuric acid was set to $\left[\mathrm{H}_{2} \mathrm{SO}_{4}\right]=10^{6}$ molecules $\mathrm{cm}^{-3}$, and with a mixing ratio of $10 \mathrm{ppt}$ of either dma or put and the calculations are performed at $278.15 \mathrm{~K}$. All calculations have also been performed using DLPNO-CCSD(T) with the smaller aug-cc-pVDZ basis set (see SI for discussion). 

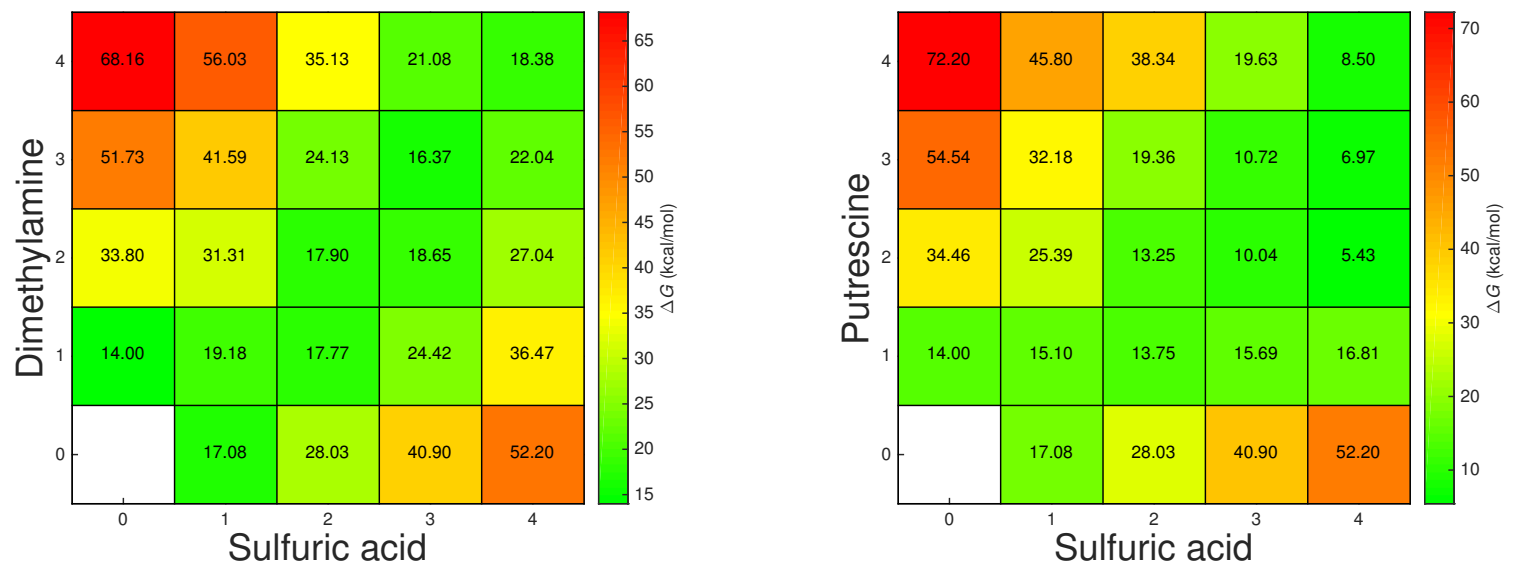

Figure 2: Gibbs free energy surfaces of the $(\mathrm{sa})_{1-4}(\mathrm{dma})_{1-4}($ left $)$ and $(\mathrm{sa})_{1-4}(\mathrm{put})_{1-4}($ right $)$ clusters, calculated at the DLPNO-CCSD(T)/aug-cc-pVTZ// $\omega$ B97X-D/6-31++G(d,p) level of theory. Calculations were performed at $278.15 \mathrm{~K}$, with $\left[\mathrm{H}_{2} \mathrm{SO}_{4}\right]=10^{6}$ molecules cm $\mathrm{cm}^{-3}$ and $10 \mathrm{ppt}$ of dimethylamine and putrescine.

The formation free energies are in all cases lower for the (sa) $)_{1-4}(\text { put })_{1-4}$ clusters compared to their $(\mathrm{sa})_{1-4}(\mathrm{dma})_{1-4}$ counterparts (except the $(\mathrm{sa})_{2}$ (base $)_{4}$ clusters). As previously noted by the work of Olenius et al., ${ }^{44}$ the free energies appear to be lowest along the diagonal on the acid - base grid. Previously, a barrierless free energy surface was obtained along the diagonal in the sa-dma system, ${ }^{44}$ but here using a more accurate quantum chemical method we obtain a slight increase in the free energy between the $(\mathrm{sa})_{3}(\mathrm{dma})_{3}$ and $(\mathrm{sa})_{4}(\mathrm{dma})_{4}$ clusters. This is predominantly caused by the large difference between the previously computed RI-CC2/augcc-pVTZ energies compared to the DLPNO-CCSD $(\mathrm{T}) /$ aug-cc-pVTZ results.

Consistent with previous work, ${ }^{44}$ we find the off-diagonal clusters with one more base than acid molecules to be higher in free energy than the corresponding clusters with one more acid than base molecules. For the $(\mathrm{sa})_{1}(\mathrm{dma})_{2},(\mathrm{sa})_{2}(\mathrm{dma})_{3}$ and $(\mathrm{sa})_{3}(\mathrm{dma})_{4}$ clusters a formation free energy of $31.31,24.13$ and $21.08 \mathrm{kcal} / \mathrm{mol}$ is found, respectively. This indicates that the $(\mathrm{sa})_{n}(\mathrm{dma})_{n+1}$ clusters show a decrease in the free energies as the clusters grow larger. For the $(\mathrm{sa})_{2}(\mathrm{dma})_{1},(\mathrm{sa})_{3}(\mathrm{dma})_{2}$ and $(\mathrm{sa})_{4}(\mathrm{dma})_{3}$ clusters a free energy of 17.77, 18.65 and $22.04 \mathrm{kcal} / \mathrm{mol}$ is found, respectively. Hence the $(\mathrm{sa})_{n+1}(\mathrm{dma})_{n}$ clusters 
show a slight increase in free energies as the clusters grow to larger sizes. This suggests that as the clusters grow larger, the difference in free energy difference between $(\mathrm{sa})_{n+1}(\mathrm{dma})_{n}$ and $(\mathrm{sa})_{n}(\mathrm{dma})_{n+1}$ clusters diminishes, and for clusters slightly beyond sizes studied here the difference might vanish.

The $(\mathrm{sa})_{1-4}(\text { put })_{1-4}$ clusters do in fact show a barrierless formation free energy profile along the diagonal. However, it is not the lowest free energy path observed in the system. Compared to the $(\mathrm{sa})_{1-4}(\mathrm{dma})_{1-4}$ clusters, the sulfuric acid - putrescine system show low or barrierless formation of clusters consisting of more acid molecules than base molecules. For instance, the $(\mathrm{sa})_{1-4}(\mathrm{put})_{1}$ clusters have formation free energies of $15.10,13.75,15.69$ and $16.81 \mathrm{kcal} / \mathrm{mol}$, respectively. In the case of the $(\mathrm{sa})_{2-4}(\mathrm{put})_{2}$ clusters, the free energies are 13.25, 10.04 and $5.43 \mathrm{kcal} / \mathrm{mol}$, respectively. This suggests that the $(\mathrm{sa})_{1-4}(\mathrm{put})_{1-4}$ clusters might be able to grow to larger sizes with only a few base molecules in the cluster via continuous addition of sulfuric acid molecules.

These patterns in the free energies are consistent with the consideration of proton transfer potential discussed in previous section. As dimethylamine is only capable of accepting a single proton, the acid - base reactions are limited more or less to a 1:1 ratio. This is also reflected in our finding that $(\mathrm{sa})_{n}(\mathrm{dma})_{n},(\mathrm{sa})_{n+1}(\mathrm{dma})_{n}$ and $(\mathrm{sa})_{n}(\mathrm{dma})_{n+1}$ clusters are significantly more stable than the rest of the clusters. This constraint is not present in the sulfuric acid - putrescine system. As each putrescine molecule is capable of accepting two protons an acid to base ratio of 2:1 also yield favourable free energies.

\subsection{Evaporation Rates and Cluster Stability}

From the quantum chemically calculated Gibbs free formation energies, we have calculated the total evaporation rates $\left(\sum \gamma\right.$ in $\left.\mathrm{s}^{-1}\right)$ of the clusters (see Figure 3$) .{ }^{41}$ The total evaporation rate is thus a sum over any molecule/cluster evaporating from the parent cluster. 

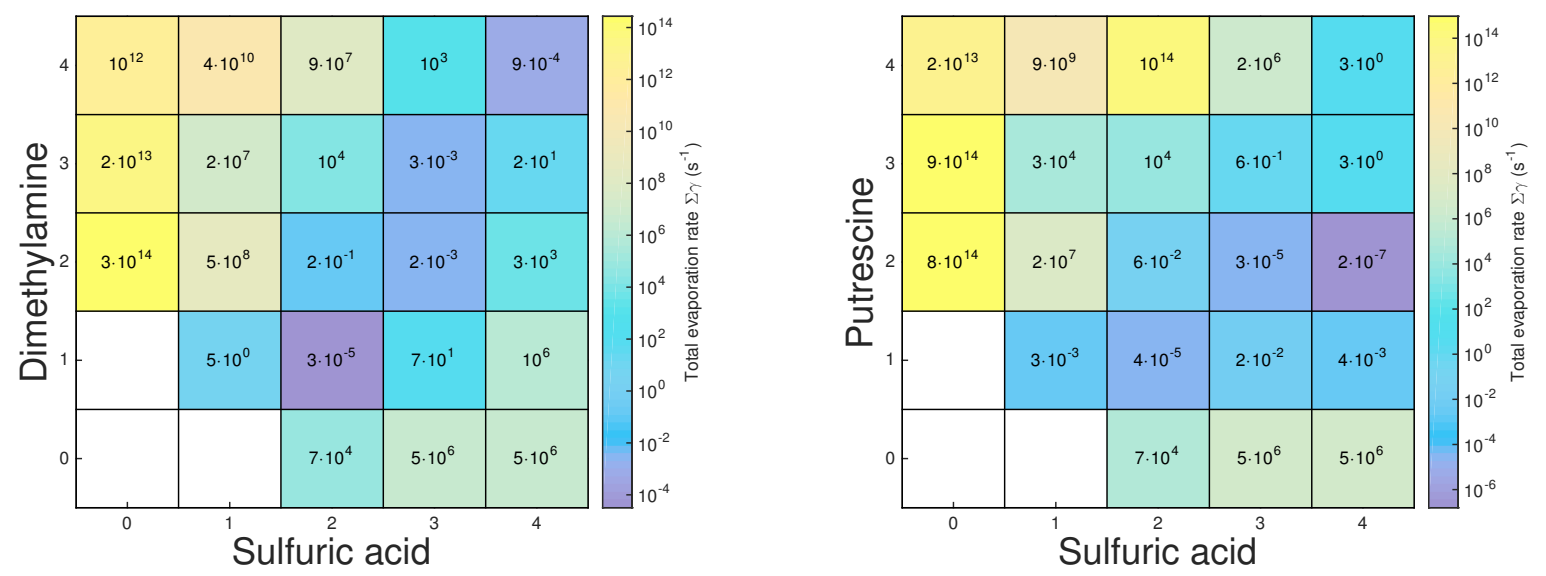

Figure 3: Total evaporation rates $\left(\sum \gamma\right.$ in $\left.\mathrm{s}^{-1}\right)$ of the $(\mathrm{sa})_{1-4}(\mathrm{dma})_{1-4}$ (left) and $(\mathrm{sa})_{1-4}(\text { put })_{1-4}$ (right) clusters, calculated at the DLPNO-CCSD(T)/aug-cc-pVTZ// $\omega$ B97X$\mathrm{D} / 6-31++\mathrm{G}(\mathrm{d}, \mathrm{p})$ level of theory. Calculations were performed at $278.15 \mathrm{~K}$.

The evaporation rates show a very similar picture as the free energy surfaces. For the $(\mathrm{sa})_{1-4}(\mathrm{dma})_{1-4}$ system, very low evaporation rates are observed along the diagonal as well as for the clusters with one more sulfuric acid than dimethylamine molecule. Combined with the free energy surfaces, this shows that the most stable clusters in the $(\mathrm{sa})_{1-4}(\mathrm{dma})_{1-4}$ system are the $(\mathrm{sa})_{n}(\mathrm{dma})_{n}$ and $(\mathrm{sa})_{n+1}(\mathrm{dma})_{n}$ clusters. Based on our updated data, in contrast to the previous study by Olenius et al., ${ }^{44}$ we cannot justify considering $(\mathrm{sa})_{n}(\mathrm{dma})_{n+1}$ clusters as stable against evaporation.

For the (sa) $)_{1-4}(\text { put })_{1-4}$ system, it can be seen that even the small (sa) $)_{1}(\mathrm{put})_{1}$ cluster can be considered stable at the considered conditions. In general, we find all the (sa) ${ }_{1-4}(\mathrm{put})_{1}$ and $(\mathrm{sa})_{2-4}(\text { put })_{2}$ clusters to have very low evaporation rates. Furthermore, the diagonal $(\mathrm{sa})_{n}(\text { put })_{n}$ clusters and the $(\mathrm{sa})_{4}$ (put) $)_{3}$ cluster also show relatively low evaporation rates. This indicates that all clusters consisting of $(\mathrm{sa})_{5}(\mathrm{put})_{1-5}$ might be considered stable against evaporation.

To get further insight into the stability of the $(\mathrm{sa})_{1-4}(\mathrm{put})_{1-4}$ clusters we performed measurements using ElectroSpray Ionization Atmospheric Pressure interface Time-Of-Flight 
mass spectrometry (ESI-APi-TOF). Negatively charged cluster were produced by electrospray and analysed by APi-TOF. As putrescine is a highly toxic compound and it requires strict precautions for safe handling, we optimized the experimental set-up using cadaverine (cad) and carried out the experiments on both sa-put and sa-cad clusters. Figure 4 shows the measured ESI-APi-TOF mass spectra.

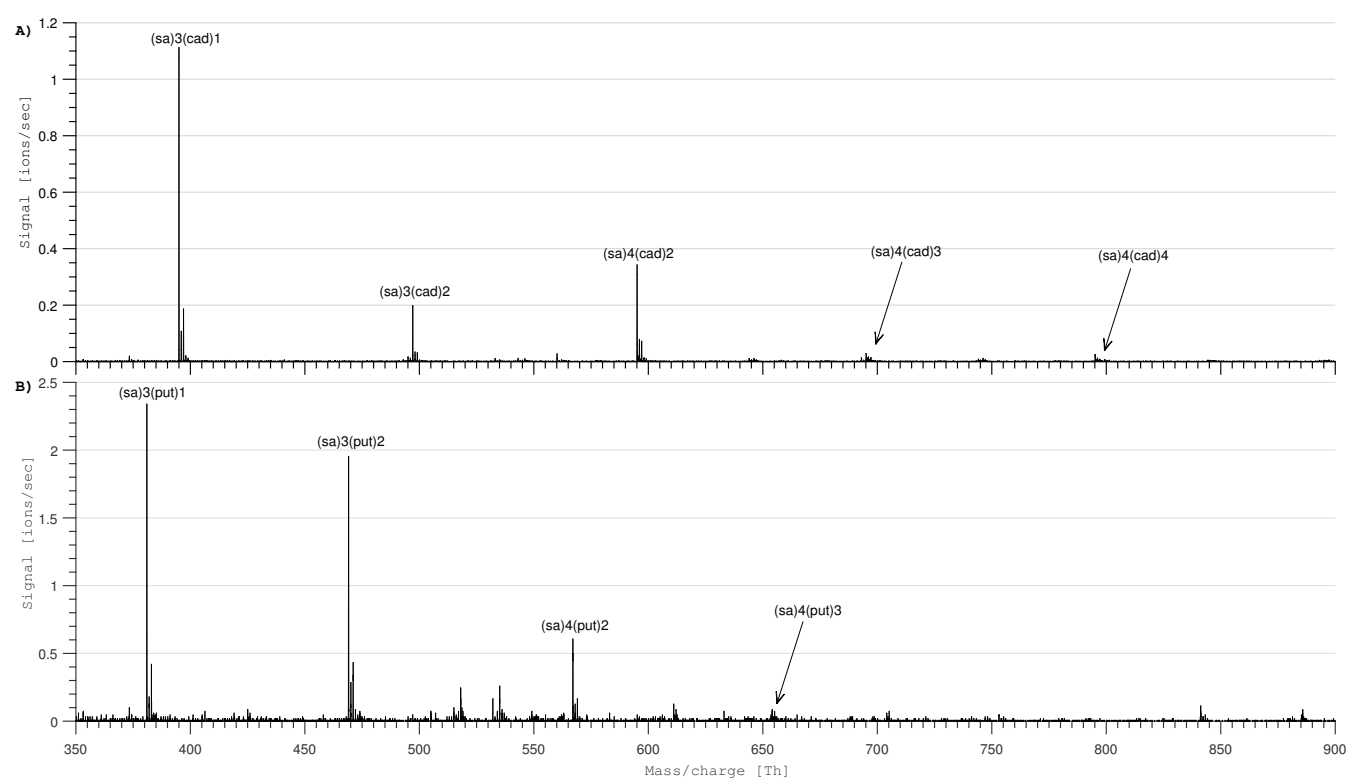

Figure 4: Mass spectra of the $(\mathrm{sa})_{1-4}(\mathrm{put})_{1-4}(\mathrm{~A})$ and $(\mathrm{sa})_{1-4}(\mathrm{put})_{1-4}(\mathrm{~B})$ clusters generated and measured using ESI-APi-TOF.

The smallest negatively charged clusters containing only 1-2 sulfuric acid and 1-2 bases are too unstable and cannot be detected by the APi-TOF. ${ }^{50}$ Indeed for negatively charged $(\mathrm{sa})_{1-2}(\mathrm{dma})_{1-2}$ clusters the evaporation rates are at least seven order of magnitude higher than for the corresponding neutral clusters, ${ }^{51}$ and we can expect a similar trend for $(\mathrm{sa})_{1-2}(\mathrm{put})_{1-2}$ and $(\mathrm{sa})_{1-2}(\mathrm{cad})_{1-2}$ clusters. The mass spectra of sa-put and sa-cad clusters are similar, we detected the $(\mathrm{sa})_{3}$ (base), $(\mathrm{sa})_{3}(\text { base })_{2},(\mathrm{sa})_{4}(\text { base })_{2}$ clusters (base $=$ put or cad). For cadaverine we also detected the $(\mathrm{sa})_{4}(\mathrm{cad})_{4}$ that we did not observe for the putrescine, probably due to the more noisy spectrum. For both bases larger clusters (with more than 5 sa) were observed, up to $(\mathrm{sa})_{5}(\mathrm{put})_{4}$ and $(\mathrm{sa})_{7}(\mathrm{cad})_{5}$ clusters. The detected clusters have compositions for which the calculated evaporation rates are low, further indicating that these clusters are 
in fact very stable. However, we were unable to detect the $(\mathrm{sa})_{4}$ (put) cluster, even though our calculation suggests it has a low evaporation rate, and only traces of the $(\mathrm{sa})_{4}(\mathrm{cad})$ cluster.

\subsection{New Particle Formation Rates}

We have simulated the new particle formation rates of the $(\mathrm{sa})_{1-4}(\mathrm{put})_{1-4}$ and $(\mathrm{sa})_{1-4}(\mathrm{dma})_{1-4}$ cluster systems with sulfuric acid concentration in the range $\left[\mathrm{H}_{2} \mathrm{SO}_{4}\right]=10^{5}-10^{8}$ molecules $\mathrm{cm}^{-3}$ and at three different mixing ratios (1,5 and $\left.10 \mathrm{pptv}\right)$ of either dma or put. The simulations were performed at 278.15 K. Based on the considerations in section 3.2 and 3.3, we can determine the criteria for when a given cluster can be allowed to grow out of the system and considered as a new particle. In the case of the sulfuric acid - dimethylamine system we allow the $(\mathrm{sa})_{5}(\mathrm{dma})_{5}$ and $(\mathrm{sa})_{5}(\mathrm{dma})_{4}$ clusters to grow out of the system forming new particles. We also tested the influence of allowing the $(\mathrm{sa})_{4}(\mathrm{dma})_{5}$ clusters to grow out of the system. By including this additional nucleation pathway up to 68,8 and 2 times more particles were formed at sulfuric acid concentrations of $10^{5}, 10^{6}$ and $10^{7}$ molecules $\mathrm{cm}^{-3}$, respectively. In case of the sulfuric acid - putrescine system we allow the (sa) $)_{5}(\mathrm{put})_{1-5}$ clusters to grow out of the simulation forming new particles.

Figure 5 shows the simulated new particle formation rates for sulfuric acid clustering with dimethylamine (solid lines) and sulfuric acid clustering with putrescine (dashed lines) compared to atmospheric observations ${ }^{52-54}$ (gray dots). 

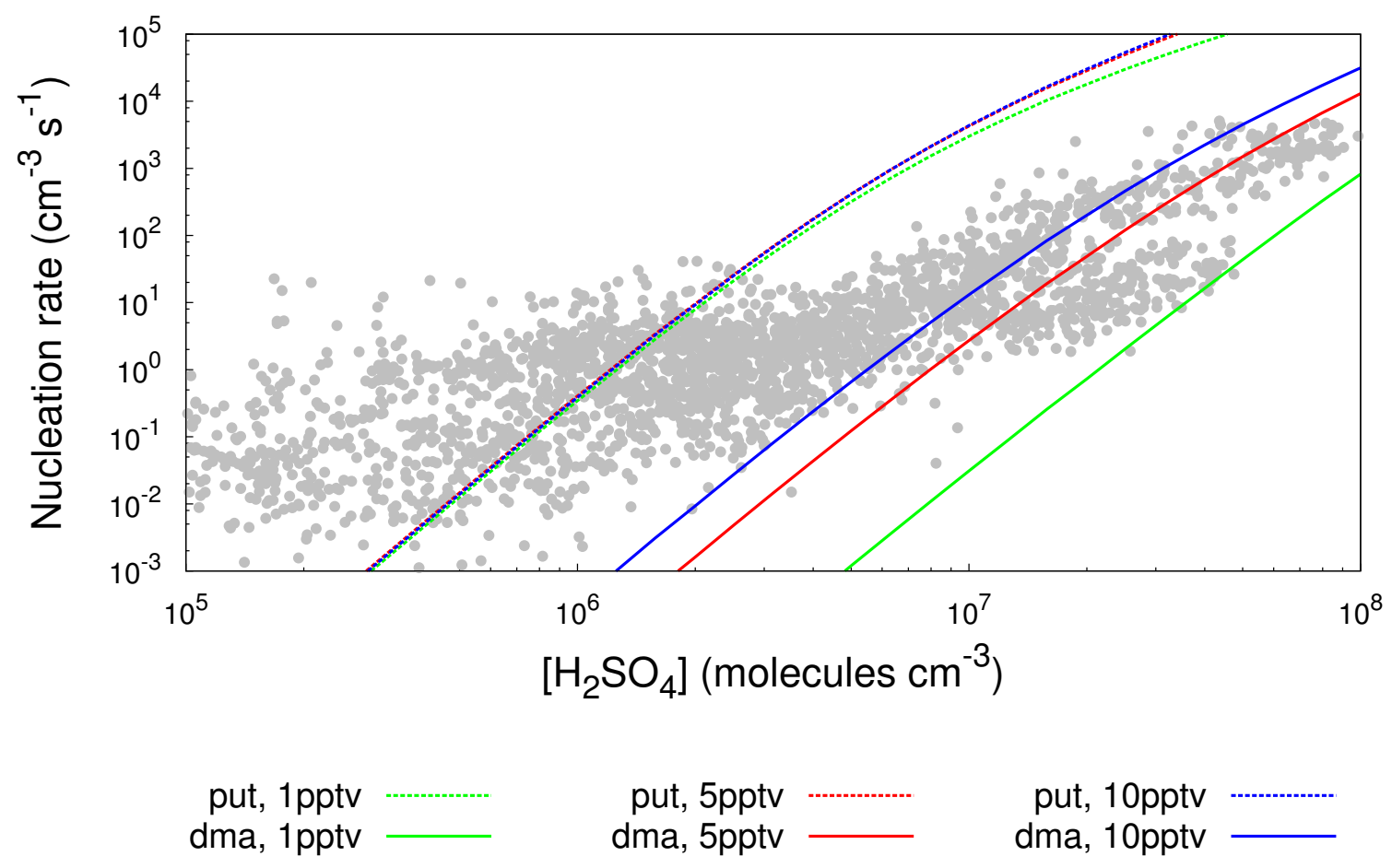

Figure 5: Simulated new particle formation rates $\left(\mathrm{cm}^{-3} \mathrm{~s}^{-1}\right)$ as a function of sulfuric acid concentration with base mixing ratios of 1 pptv (green), 5 pptv (red) and 10 pptv (blue), at 278.15K. Dashed lines correspond to putrescine (put) clusters, while full lines correspond to dimethylamine (dma) clusters. The grey dots correspond to atmospheric observations. Note that the simulations with 5 pptv and 10 pptv putrescine are practically overlapping.

The simulated new particle formation rates for the sulfuric acid - dimethylamine system are seen to reproduce the atmospheric observations at high sulfuric acid concentrations. Base mixing ratios of 1-10 pptv are seen to be able to represent different regions of the atmospheric observations. At $10 \mathrm{pptv}$ of dma the new particle formation rates are in good agreement with the observations over a range of $\left[\mathrm{H}_{2} \mathrm{SO}_{4}\right]=1 \cdot 10^{6}-1 \cdot 10^{8}$ molecules $\mathrm{cm}^{-3}$. At $5 \mathrm{pptv}$ of dma sulfuric acid concentrations in the range $\left[\mathrm{H}_{2} \mathrm{SO}_{4}\right]=5 \cdot 10^{6}-1 \cdot 10^{8}$ molecules $\mathrm{cm}^{-3}$ is required to match the observations. At 1pptv of dma a high sulfuric acid concentration (above $3 \cdot 10^{7}$ molecules $\mathrm{cm}^{-3}$ ) is required to yield quantitative agreement with the observations.

Interestingly, the formation rates in the sulfuric acid - putrescine system do not seem to depend much on the putrescine mixing ratios. Only at sulfuric acid concentrations above $10^{7}$ molecules $\mathrm{cm}^{-3}$ and $1 \mathrm{pptv}$ mixing ratio of putrescine does the curves begin to deviate. 
This is caused by the fact that putrescine binds so strongly to sulfuric acid even in the initial cluster formation steps. In the sulfuric acid - dimethylamine system, the growth is essentially limited by the formation of the $(\mathrm{sa})_{1}(\mathrm{dma})_{1}$ cluster, ${ }^{55}$ which have a finite lifetime due to its evaporation rate of $\gamma=5 \mathrm{~s}^{-1}$. In contrast, the (sa) $)_{1}$ (put) $)_{1}$ cluster is already relatively stable against evaporation $\left(\gamma=3 \cdot 10^{-3} \mathrm{~s}^{-1}\right)$ and hence the further growth is not limited by the formation of the initial (sa) $)_{1}$ (put) $)_{1}$ cluster.

The sulfuric acid - putrescine system can reproduce the atmospheric observations in the sulfuric acid concentration range around $8 \cdot 10^{5}-4 \cdot 10^{6}$ molecules $\mathrm{cm}^{-3}$. At higher sulfuric acid concentrations the simulated new particle formation rate based on the (sa) ${ }_{1-4}(\mathrm{put})_{1-4}$ exceeds observations. Even though putrescine (and other diamines) might not be very abundant in the atmosphere, they might be key species in stabilizing the initial steps in new particle formation, as the clusters are not prone to re-evaporation. These findings indicates that different amines, with different basicity, are able to explain the observed new particle formation rates at different sulfuric acid concentrations. Highly basic amines such as putrescine might explain new particle formation rates at low sulfuric acid concentrations, while more abundant, but less basic amines need a higher concentration of sulfuric acid to match the observations. Observed new particle formation events in the atmosphere are most likely not linked to a single amine, but rather a large array of different amines participate in cluster formation.

The simulated new particle formation rates yield important information, which can be compared directly to the atmospheric observations. While we have applied state-of-the-art computational methods for obtaining the free energies, the numerical values are inherently affected by the underlying choice of computational methodology. Ratios of formation rates in different systems are much less affected by the method. Thus we define the enhancement factor as the following:

$$
\text { Enhancement Factor }=\frac{J_{\text {put }}}{J_{\text {dma }}}
$$


Figure 6 shows the enhancement in the new particle formation rate by exchanging the base from dimethylamine to putrescine.
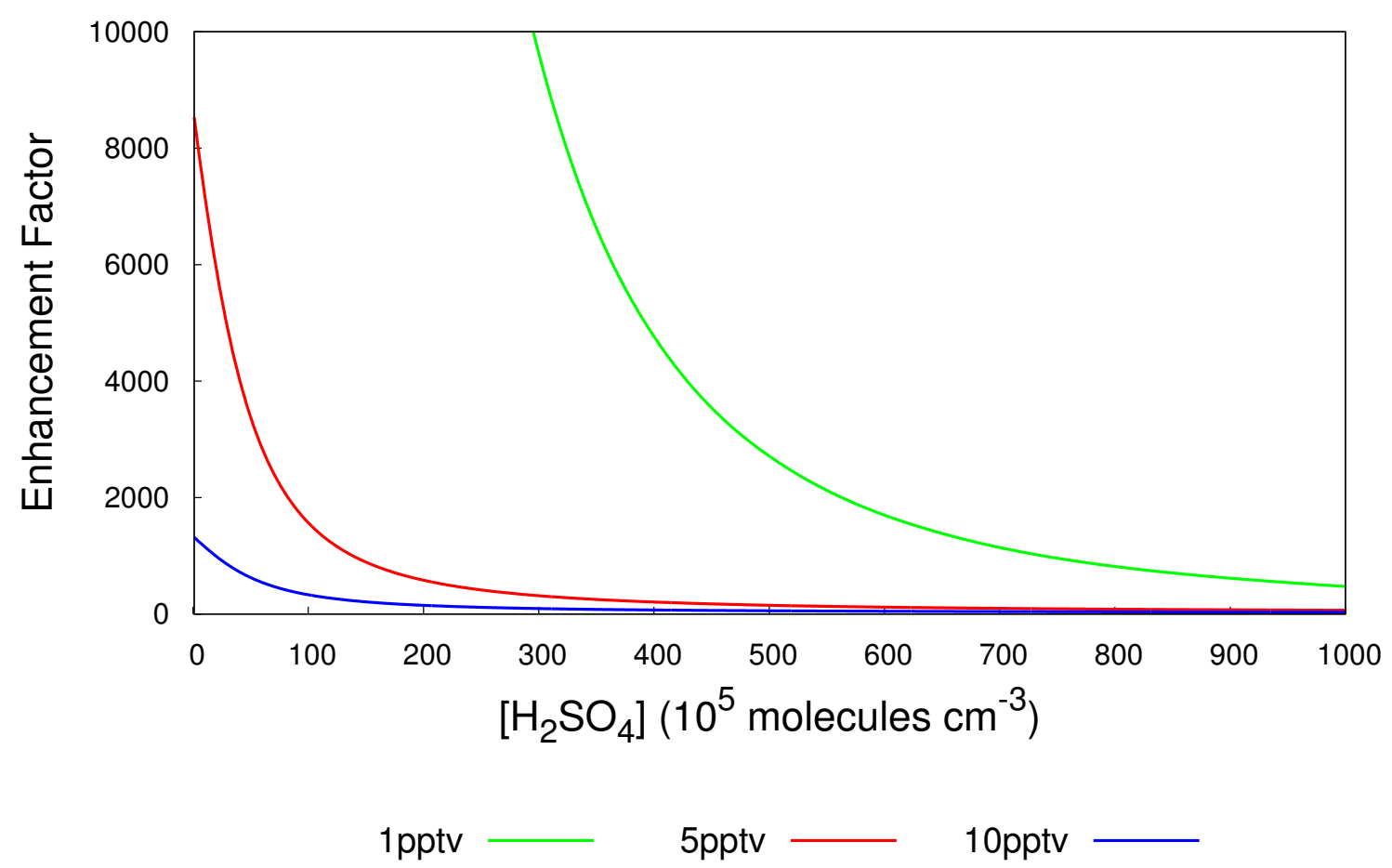

Figure 6: Enhancement in new particle formation rates as a function of sulfuric acid concentration with base mixing ratios of 1 ppt (green), 5 ppt (red) and 10 ppt (blue) and at $278.15 \mathrm{~K}$.

At very low mixing ratios (1 pptv) and low sulfuric acid concentrations $\left(10^{5}\right.$ molecules $\mathrm{cm}^{-3}$ ) a $10^{6}$ times increase in the new particle formation rates is observed, when replacing dma with putrescine. At higher amine mixing ratios (5 pptv and 10 pptv) and sulfuric acid concentration of $10^{5}$ molecules $\mathrm{cm}^{-3}$, the enhancement is reduced to a factor of $10^{4}$ and $10^{3}$ in the new particle formation rates, respectively. At higher sulfuric acid concentrations the enhancement factor is seen to smoothly decrease and converge towards a similar value. Based on flow tube experiments Jen et al. ${ }^{19}$ found that diamines produced 10 times more particle than dimethylamine in the limit of high sulfuric acid concentration $\left(2 \cdot 10^{9}\right.$ molecules $\mathrm{cm}^{-3}$ ) and low amine mixing ratio (1 pptv). At $\left[\mathrm{H}_{2} \mathrm{SO}_{4}\right]=2 \cdot 10^{9}$ molecules $\mathrm{cm}^{-3}$ and 1,5 or 10 pptv mixing ratios of bases, we find an enhancement in the new particle formation rate of 
15.9, 9.3 and 7.2, respectively (data not shown in the graph). Hence, the simulation results presented here are in good agreement with experimental values at the limit of high sulfuric acid concentration.

\subsection{Cluster Growth Paths}

To understand the mechanism for the formation of new particles, we have studied the cluster growth paths for the $(\mathrm{sa})_{1-4}(\mathrm{put})_{1-4}$ and $(\mathrm{sa})_{1-4}(\mathrm{dma})_{1-4}$ clusters. Figure 7 presents the dominant growth path for the two systems. In Figure 7 we use the median values in the studied concentration ranges (concentration of sulfuric acid was set to $\left[\mathrm{H}_{2} \mathrm{SO}_{4}\right]=10^{6}$ molecules $\mathrm{cm}^{-3}$, and a mixing ratio to $5 \mathrm{ppt}$ of either dma or put), corresponding to the red curves in Figures 5 and 6 . The simulations were performed at $278.15 \mathrm{~K}$.
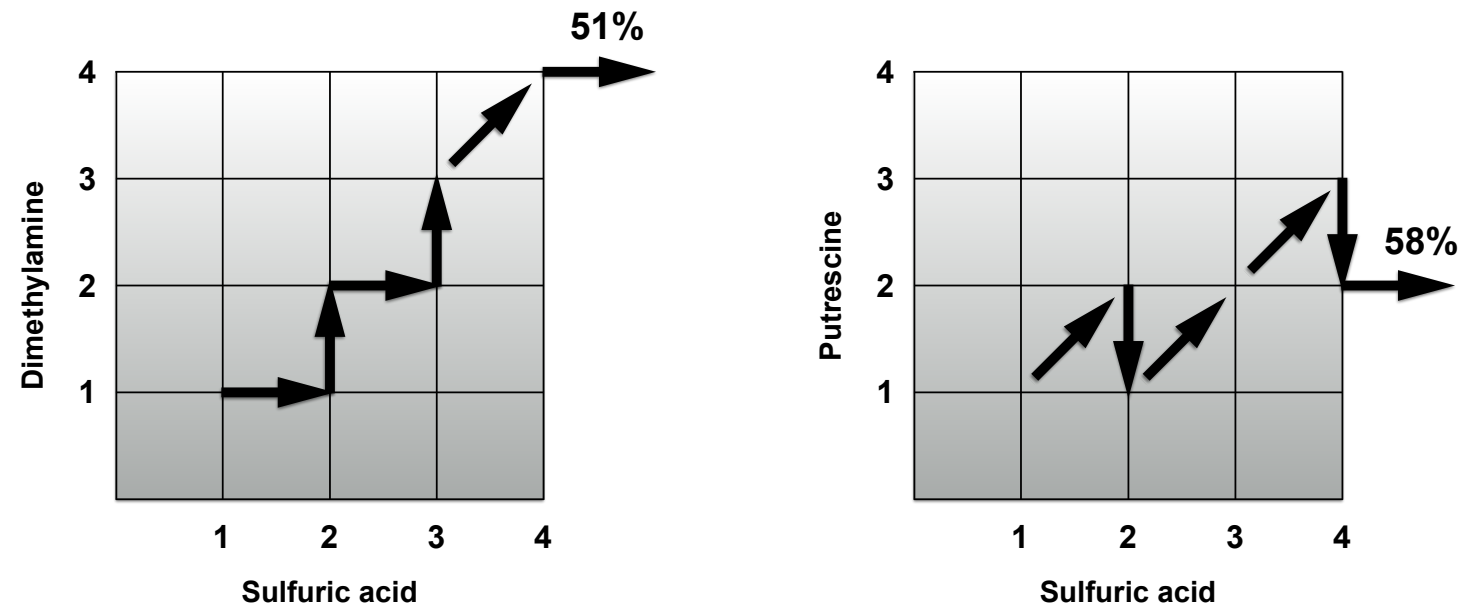

Figure 7: Primary growth routes in the $(\mathrm{sa})_{1-4}(\mathrm{put})_{1-4}$ and $(\mathrm{sa})_{1-4}(\mathrm{dma})_{1-4}$ cluster systems, at $278.15 \mathrm{~K}$. Concentration of sulfuric acid was set to $\left[\mathrm{H}_{2} \mathrm{SO}_{4}\right]=10^{6}$ molecules $\mathrm{cm}^{-3}$, and a mixing ratio of either dma or put to 5 pptv).

The sulfuric acid - dimethylamine system is seen to grow primarily (more than 97\%) via monomer addition until it reaches the $(\mathrm{sa})_{3}(\mathrm{dma})_{3}$ cluster. $56 \%$ of the $(\mathrm{sa})_{4}(\mathrm{dma})_{4}$ cluster is found to originate from the collision between a $(\mathrm{sa})_{3}(\mathrm{dma})_{3}$ and a $(\mathrm{sa})_{1}(\mathrm{dma})_{1}$ cluster. A $33 \%$ contribution to the $(\mathrm{sa})_{4}(\mathrm{dma})_{4}$ cluster is originating from the collision 
between a $(\mathrm{sa})_{4}(\mathrm{dma})_{3}$ cluster and a dma molecule. A $10 \%$ contribution is found from the self-coagulation of two $(\mathrm{sa})_{2}(\mathrm{dma})_{2}$ clusters. $51 \%$ of the growth out of the system is found to originate from the addition of a sulfuric acid monomer to the $(\mathrm{sa})_{4}(\mathrm{dma})_{4}$ cluster. The remaining major contributions to the flux out of the system is from cluster reactions between the $(\mathrm{sa})_{3}(\mathrm{dma})_{3}$ cluster and $(\mathrm{sa})_{2}(\mathrm{dma})_{1}(33 \%)$ or $(\mathrm{sa})_{2}(\mathrm{dma})_{2}(13 \%)$. The difference between our simulated growth path and those previously reported by Olenius et al. ${ }^{44}$ can be attributed to the difference in the calculated formation free energy of the smallest (sa) $)_{1}(\mathrm{dma})_{1}$ cluster. In our calculations the $(\mathrm{sa})_{1}(\mathrm{dma})_{1}$ cluster is significantly less stable and hence the primary initial growth path is due to monomer collisions compared to consecutive collisions between $(\mathrm{sa})_{1}(\mathrm{dma})_{1}$ clusters.

The putrescine clusters show a significantly different formation route compared to the dimethylamine clusters. In contrast to the case of dimethylamine, the initially formed $(\mathrm{sa})_{1}(\mathrm{put})_{1}$ cluster is so stable that $(\mathrm{sa})_{1}$ (put) $)_{1}$ collisions contribute to the cluster growth. However, some of the smaller clusters are significantly more stable than the large $(\mathrm{sa})_{n}(\mathrm{put})_{n}$ clusters, and the main growth path is thereby not along the diagonal, but via a complex route of $(\mathrm{sa})_{1}$ (put) $)_{1}$ cluster addition reactions and evaporation of putrescine molecules. The flux out of the system is predominantly $(58 \%)$ via collision of $(\mathrm{sa})_{4}(\mathrm{put})_{2}$ clusters with $(\mathrm{sa})_{1}(\mathrm{put})_{1}$ clusters. The remaining contributions comes from $(\mathrm{sa})_{3}(\mathrm{put})_{2}$ clusters colliding with either $(\mathrm{sa})_{2}(\text { put })_{2}$ clusters $(14 \%),(\mathrm{sa})_{2}(\text { put })_{1}$ clusters $(11 \%)$ or with a sulfuric acid molecule $(6 \%)$. The stronger interaction between sulfuric acid and putrescine compared to dimethylamine allows for more cluster reactions to take place in the system. The complex growth route in the $(\mathrm{sa})_{n}(\mathrm{put})_{n}$ clusters is a consequence of the extraordinary high stability of the $(\mathrm{sa})_{1}(\mathrm{put})_{1}$, $(\mathrm{sa})_{1-4}(\mathrm{put})$ and $(\mathrm{sa})_{2-4}(\text { put })_{2}$ clusters compared to the larger $(\mathrm{sa})_{3}(\mathrm{put})_{3}$ and $(\mathrm{sa})_{4}(\mathrm{put})_{4}$ clusters.

Previously, it has been inferred that new particles can form with just a single diamine and several sulfuric acid molecules. ${ }^{19}$ Our simulations here corroborate this hypothesis as we find very stable clusters consisting of only a single putrescine and up to four sulfuric 
acid molecules. This could indicate that diamines might be very important species in the initial steps in new particle formation as only a single base molecule is required to form a cluster that survives long enough to grow. Diamines might be a key species in forming the very initial cluster, and less basic, but more abundant amines can subsequently assist the new particle formation process by attaching to the sulfuric acid - diamine seed cluster. After reaching a stable cluster, the subsequent growth to larger sizes is most likely caused by condensation of highly oxidized multifunctional compounds (HOMs), omnipresent in the atmosphere.

\section{4 - Conclusions}

We have investigated the molecular interaction between sulfuric acid and the diamine putrescine and compared the results to the sulfuric acid - dimethylamine system. The clusters containing putrescine were found to be significantly more ionic than the clusters containing dimethylamine. We find that clusters consisting of 1-2 putrescine molecules and up to five sulfuric acid molecules are stable against evaporation. This finding was further corroborated by ESI-APi-TOF measurements. The higher stability of the sulfuric acid - putrescine clusters yield an enhancement in the new particle formation rates up to six orders of magnitude compared to sulfuric acid - dimethylamine clusters. Our findings suggests that diamines or compounds with similar basicity might be key players in the initial steps in new particle formation. More abundant and less basic amines could then contribute to the new particle formation process by further stabilizing the initially formed cluster. Subsequently, the growth of the initially stabilized cluster is most likely governed by uptake of highly oxidized multifunctional organic compounds. 


\section{Acknowledgement}

J.E thanks the Carlsberg foundation for financial support. We thank the Academy of Finland and ERC project 692891-DAMOCLES for funding and the CSC-IT Center for Science in Espoo, Finland, for computational resources.

\section{Supporting Information Available}

The following is available as supporting information:

- xyz-files of the studied molecular structures at the $\omega$ B97X-D/6-31++G(d,p) and PW91/6$311++\mathrm{G}(3 \mathrm{df}, 3 \mathrm{pd})$ levels of theory.

- Benchmark of the DLPNO-CCSD(T) binding energies.

- Analysis of the quasi-harmonic approximation.

- Further details about ACDC simulations.

- Comparison between the DLPNO-CCSD(T)/aug-cc-pVTZ//wB97X-D/6-31++G(d,p) and PW91/6-311++G(3df,3pd) potential energy surfaces.

- All calculated Gibbs free energies.

This material is available free of charge via the Internet at http://pubs.acs.org/.

\section{References}

(1) IPCC, 2013: Climate Change 2013: The Physical Science Basis. Contribution of Working Group I to the Fifth Assessment Report of the Intergovernmental Panel on Climate Change [Stocker, T.F., D. Qin, G.-K. Plattner, M. Tignor, S.K. Allen, J. Boschung, A. Nauels, Y. Xia, V. Bex and P.M. Midgley (eds.)]. Cambridge University Press, Cambridge, United Kingdom and New York, NY, USA, 1535 pp. 
(2) Merikanto, J.; Spracklen, D. V.; Mann, G. W.; Pickering, S. J.; Carslaw, K. S. Impact of nucleation on global CCN. Atmos. Chem. Phys. 2009, 9, 8601-8616.

(3) Sipilä, M.; Berndt, T.; Petäjä, T.; Brus, D.; Vanhanen, J.; Stratmann, F.; Patokoski, J.; Mauldin, R. L.; Hyvrinen, A.-P.; Lihavainen, H. et al. The Role of Sulfuric Acid in Atmospheric Nucleation. Science 2010, 327, 1243-1246.

(4) Kulmala, M.; Vehkamäki, H.; Petäjä, T.; Maso, M. D.; Lauri, A.; Kerminen, V.-M.; Birmili, W.; McMurry, P. Formation and Growth Rates of Ultrafine Atmospheric Particles: A Review of Observations. J. Aerosol Sci. 2004, 35, 143 - 176.

(5) Kirkby, J.; Curtius, J.; Almeida, J.; Dunne, E.; Duplissy, J.; Ehrhart, S.; Franchin, A.; Gagne, S.; Ickes, L.; Krten, A. et al. Role of Sulphuric Acid, Ammonia and Galactic Cosmic Rays in Atmospheric Aerosol Nucleation. Nature 2011, 476, 429 - 433.

(6) Weber, R. J.; Marti, J. J.; McMurry, P. H.; Eisele, F. L.; Tanner, D. J.; Jefferson, A. Measured Atmospheric New Particle Formation Rates: Implications for Nucleation Mechanisms. Chem. Eng. Comm. 1996, 151, 53-64.

(7) Almeida, J.; Schobesberger, S.; Kürten, A.; Ortega, I. K.; Kupiainen-Määttä, O.; Praplan, A. P.; Adamov, A.; Amorim, A.; Bianchi, F.; Breitenlechner, M. et al. Molecular Understanding of Sulphuric Acid-Amine Particle Nucleation in the Atmosphere. Nature 2013, 502, 359-363.

(8) Kürten, A.; Jokinen, T.; Simon, M.; Sipil, M.; Sarnela, N.; Junninen, H.; Adamov, A.; Almeida, J.; Amorim, A.; Bianchi, F. et al. Neutral Molecular Cluster Formation of Sulfuric Acid-Dimethylamine Observed in Real Time under Atmospheric Conditions. Proc. Natl. Acad. Sci. U.S.A. 2014, 111, 15019-15024.

(9) Kurtén, T.; Loukonen, V.; Vehkamäki, H.; Kulmala, M. Amines are Likely to Enhance Neutral and Ion-induced Sulfuric Acid-water Nucleation in the Atmosphere More Effectively than Ammonia. Atmos. Chem. Phys. 2008, 8, 4095-4103. 
(10) Jen, C. N.; McMurry, P. H.; Hanson, D. R. Stabilization of Sulfuric acid Dimers by Ammonia, Methylamine, Dimethylamine, and Trimethylamine. J Geophys. Res. Atmos. 2014, 119, 7502-7514.

(11) Elm, J.; Jen, C. N.; Kurtén, T.; Vehkamäki, H. Strong Hydrogen Bonded Molecular Interactions between Atmospheric Diamines and Sulfuric Acid. J. Phys. Chem. A 2016, 120, 3693-3700.

(12) Ge, X.; Wexler, A. S.; Clegg, S. L. Atmospheric Amines - Part I. A Review. Atmos. Environ. 2011, 45, 524-546.

(13) Sipilä, M.; Sarnela, N.; Jokinen, T.; Junninen, H.; Hakala, J.; Rissanen, M. P.; Praplan, A.; Simon, M.; Kürten, A.; Bianchi, F. et al. Bisulfate - Cluster Based Atmospheric Pressure Chemical Ionization Mass Spectrometer for High-Sensitivity $(<100$ ppqV) Detection of Atmospheric Dimethyl Amine: Proof-of-concept and First Ambient Data from Boreal Forest. Atmos. Meas. Tech. 2015, 8, 4001-4011.

(14) Kieloaho, A.-J.; Hellén, H.; Hakola, H.; Manninen, H. E.; Nieminen, T.; Kulmala, M.; Pihlatie, M. Gas-phase Alkylamines in a Boreal Scots Pine Forest Air. Atmos. Environ. 2013, 80, 369-377.

(15) Hellén, H.; Kieloaho, A.-J.; Hakola, H. Gas-phase Alkyl Amines in Urban Air; Comparison with a Boreal Forest Site and Importance for Local Atmospheric Chemistry. Atmos. Environ. 2014, 94, 192-197.

(16) Kieloaho, A.-J.; Launiainen, M. P. S.; Kulmala, M.; Riekkola, M.-L.; Parshintsev, J.; andT. Vesala, I. M.; Heinonsalo, J. Soil Concentrations and Soil-Atmosphere Exchange of Alkylamines in a Boreal Scots Pine Forest. Biogeosciences Discuss. 2017, doi:10.5194/bg-2016-363,.

(17) Niemi, K.; Häggman, H.; Sarjala, T. Effects of Exogenous Diamines on the Interaction 
between Ectomycorrhizal Fungi and Adventitious Root Formation in Scots Pine in Vitro. Tree Physiol. 2002, 22, 373-381.

(18) Valdés-Santiago, L.; Ruiz-Herrera, J. Stress and Polyamine Metabolism in Fungi. Front. Chem. 2014, 1, 1-10.

(19) Jen, C. N.; Bachman, R.; Zhao, J.; McMurry, P. H.; Hanson, D. R. Diamine-Sulfuric Acid Reactions are a Potent Source of New Particle Formation. Geophys. Res. Lett. 2016, 43, 867-873.

(20) Gaussian 09, Revision B.01, M. J. Frisch, G. W. Trucks, H. B. Schlegel, G. E. Scuseria, M. A. Robb, J. R. Cheeseman, G. Scalmani, V. Barone, B. Mennucci, G. A. Petersson, et al., Gaussian, Inc., Wallingford CT, 2010.

(21) Chai, J.; Martin, H. Long-Range Corrected Hybrid Density Functionals with Damped Atom-Atom Dispersion Corrections. Phys. Chem. Chem. Phys. 2008, 10, 6615-6620.

(22) Elm, J.; Bilde, M.; Mikkelsen, K. V. Assessment of Binding Energies of Atmopsheric Clusters. Phys. Chem. Chem. Phys 2013, 15, 16442-16445.

(23) Elm, J.; Kristensen, K. Basis Set Convergence of the Binding Energies of Strongly Hydrogen-Bonded Atmospheric Clusters. Phys. Chem. Chem. Phys 2017, 19, 11221133.

(24) Elm, J.; Mikkelsen, K. V. Computational Approaches for Efficiently Modelling of Small Atmospheric Clusters. Chem. Phys. Lett. 2014, 615, 26-29.

(25) Myllys, N.; Elm, J.; Kurtén, T. Density Functional Theory Basis Set Convergence of Sulfuric Acid-Containing Molecular Clusters. Comp. Theor. Chem. 2016, 1098, 1-12.

(26) Nadykto, A. B.; Yu, F.; Jakovleva, M. V.; Herb, J.; Xu, Y. Amines in the Earth's Atmosphere: A Density Functional Theory Study of the Thermochemistry of PreNucleation Clusters. Entropy 2011, 13, 554-569. 
(27) Nadykto, A. B.; Herb, J.; Yu, F.; Xu, Y. Enhancement in the Production of Nucleating Clusters due to Dimethylamine and Large Uncertainties in the Thermochemistry of Amine-Enhanced Nucleation. Chem. Phys. Lett. 2014, 609, 42-49.

(28) Nadykto, A. B.; Herb, J.; Yu, F.; Xu, Y.; Nazarenko, E. S. Estimating the Lower Limit of the Impact of Amines on Nucleation in the Earths Atmosphere. Entropy 2015, 17, $2764-2780$.

(29) Herb, J.; Nadykto, A. B.; Yu, F. Large Ternary Hydrogen-bonded Pre-nucleation Clusters in the Earth's Atmosphere. Chem. Phys. Lett. 2011, 518, 7-14.

(30) Werner, H.; Adler, T. B.; Manby, F. R. General Orbital Invariant MP2-F12 Theory. J. Chem. Phys. 2007, 126, 164102.

(31) Adler, T. B.; Knizia, G.; Werner, H. A Simple and Efficient CCSD(T)-F12 Approximation. J. Chem. Phys. 2007, 127, 221106.

(32) Knizia, G.; Adler, T. B.; Werner, H. Simplified CCSD(T)-F12 Methods: Theory and Benchmarks. J. Chem. Phys. 2009, 130, 054104.

(33) Peterson, K. A.; Adler, T. B.; Werner, H. Systematically Convergent Basis Sets for Explicitly Correlated Wavefunctions: The Atoms H, He, B-Ne, and Al-Ar. J. Chem. Phys. 2008, 128, 084102.

(34) MOLPRO, version 2012.1, a package of ab initio programs, H.-J. Werner, P. J. Knowles, G. Knizia, F. R. Manby, M. Schtz, P. Celani, T. Korona, R. Lindh, A. Mitrushenkov, G. Rauhut, K. R. Shamasundar, T. B. Adler, R. D. Amos, A. Bernhardsson, A. Berning, D. L. Cooper, M. J. O. Deegan, A. J. Dobbyn, F. Eckert, E. Goll, C. Hampel, A. Hesselmann, G. Hetzer, T. Hrenar, G. Jansen, C. Kppl, Y. Liu, A. W. Lloyd, R. A. Mata, A. J. May, S. J. McNicholas, W. Meyer, M. E. Mura, A. Nicklass, D. P. O'Neill, P. Palmieri, D. Peng, K. Pflger, R. Pitzer, M. Reiher, T. Shiozaki, H. Stoll, A. J. Stone, R. Tarroni, T. Thorsteinsson, and M. Wang, , see http://www.molpro.net. 
(35) Riplinger, C.; Neese, F. An Efficient and Near Linear Scaling Pair Natural Orbital Based Local Coupled Cluster Method. J. Chem. Phys. 2013, 138, 034106.

(36) Riplinger, C.; Sandhoefer, B.; Hansen, A.; Neese, F. Natural Triple Excitations in Local Coupled Cluster Calculations with Pair Natural Orbitals. J. Chem. Phys. 2013, 139, 134101.

(37) Neese F., WIREs Comput Mol Sci 2012, 2: 73-78 doi: 10.1002/wcms.81.

(38) Grimme, S. Supramolecular Binding Thermodynamics by Dispersion-corrected Density Functional Theory. Chem. Eur. J. 2012, 18, 9955-9964.

(39) I. Funes-Ardois, R. Paton, GoodVibes: GoodVibes v1.0.1, 2016, doi:http://dx.doi.org/10.5281/zenodo.60811.

(40) Loukonen, V.; Kurtén, T.; Ortega, I. K.; Vehkamäki, H.; Pádua, A. A. H.; Sellegri, K.; Kulmala, M. Enhancing Effect of Dimethylamine in Sulfuric Acid Nucleation in the Presence of Water - A Computational Study. Atmos. Chem. Phys. 2010, 10, 49614974.

(41) Ortega, I. K.; Kupiainen, O.; Kurtén, T.; Olenius, T.; Wilkman, O.; McGrath, M. J.; Loukonen, V.; Vehkamäki, H. From Quantum Chemical Formation Free Energies to Evaporation Rates. Atmos. Chem. Phys. 2012, 12, 225-235.

(42) Elm, J.; Fard, M.; Bilde, M.; Mikkelsen, K. V. Interaction of Glycine with Common Atmospheric Nucleation Precursors. J. Phys. Chem. A 2013, 117, 12990-12997.

(43) McGrath, M. J.; Olenius, T.; Ortega, I. K.; Loukonen, V.; Paasonen, P.; Kurtén, T.; Kulmala, M.; Vehkamäki, H. Atmospheric Cluster Dynamics Code: A Flexible Method for Solution of the Birth-Death Equations. Atmos. Chem. Phys. 2012, 12, 2345-2355. 
(44) Olenius, T.; Kupiainen-Määttä, O.; Ortega, I. K.; Kurtén, T.; Vehkamäki, H. Free Energy Barrier in the Growth of Sulfuric Acid-Ammonia and Sulfuric Acid-Dimethylamine Clusters. J. Chem. Phys. 2013, 139, doi: 10.1063/1.4819024.

(45) Riccobono, F.; Schobesberger, S.; Scott, C. E.; Dommen, J.; Ortega, I. K.; Rondo, L.; Almeida, J.; Amorim, A.; Bianchi, F.; Breitenlechner, M. et al. Oxidation Products of Biogenic Emissions Contribute to Nucleation of Atmospheric Particles. Science 2014, 344, 717-721.

(46) Kirkby, J.; Duplissy, J.; Sengupta, K.; Frege, C.; Gordon, H.; Williamson, C.; Heinritzi, M.; Simon, M.; Yan, C.; Almeida, J. et al. Ion-Induced Nucleation of Pure Biogenic Particles. Nature 2016, 533, 521-526.

(47) Dal Maso, M.; Hyvrinen, A.; Komppula, M.; Tunved, P.; Kerminen, V.-M.; Lihavainen, H.; Viisanen, Y.; Hansson, H.-C.; Kulmala, M. Annual and Interannual Variation in Boreal Forest Aerosol Particle Number and Volume Concentration and their Connection to Particle Formation. Tellus B 2008, 60, 495-508.

(48) Kontkanen, J.; Lehtipalo, K.; Ahonen, L.; Kangasluoma, J.; Manninen, H. E.; Hakala, J.; Rose, C.; Sellegri, K.; Xiao, S.; Wang, L. et al. Measurements of Sub-3 nm Particles using a Particle Size Magnifier in Different Environments: From Clean Mountain Top to Polluted Megacities. Atmos. Chem. Phys. 2017, 17, 2163-2187.

(49) Junninen, H.; Ehn, M.; Petäjä, T.; Luosujärvi, L.; Kotiaho, T.; Kostiainen, R.; Rohner, U.; Gonin, M.; Fuhrer, K.; Kulmala, M. et al. A high-resolution Mass Spectrometer to Measure Atmospheric Ion Composition. Atmos. Meas. Tech. 2010, 3, 10391053.

(50) Bianchi, F.; Praplan, A. P.; Sarnela, N.; Dommen, J.; Krten, A.; Ortega, I. K.; Schobesberger, S.; Junninen, H.; Simon, M.; Trstl, J. et al. Insight into AcidBase Nucleation 
Experiments by Comparison of the Chemical Composition of Positive, Negative, and Neutral Clusters. Environ. Sci. Technol. 2014, 48, 13675-13684.

(51) Ortega, I. K.; Olenius, T.; Kupiainen-Määttä, O.; Loukonen, V.; Kurtn, T.; Vehkamäki, H. Electrical Charging Changes the Composition of Sulfuric AcidAmmonia/Dimethylamine Clusters. Atmos. Chem. Phys. 2014, 14, 7995-8007.

(52) Sihto, S.-L.; Kulmala, M.; Kerminen, V.-M.; Dal Maso, M.; Petäjä, T.; Riipinen, I.; Korhonen, H.; Arnold, F.; Janson, R.; Boy, M. et al. Atmospheric Sulphuric Acid and Aerosol Formation: Implications from Atmospheric Measurements for Nucleation and Early Growth Mechanisms. Atmos. Chem. Phys. 2006, 6, 4079-4091.

(53) Kuang, C.; McMurry, P. H.; McCormick, A. V.; Eisele, F. L. Dependence of Nucleation Rates on Sulfuric Acid Vapor Concentration in Diverse Atmospheric Locations. J. Geophys. Res. 2008, 113, D10209.

(54) Paasonen, P.; Nieminen, T.; Asmi, E.; Manninen, H. E.; Petäjä, T.; Plass-Dülmer, C.; Flentje, H.; Birmili, W.; Wiedensohler, A.; Hõrrak, U. et al. On the Roles of Sulphuric Acid and Low-volatility Organic Vapours in the Initial Steps of Atmospheric New Particle Formation. Atmos. Chem. Phys 2010, 10, 11223-11242.

(55) Myllys, N.; Elm, J.; Halonen, R.; Kurtén, T.; Vehkamäki, H. Coupled Cluster Evaluation of the Stability of Atmospheric Acid-Base Clusters with up to 10 Molecules. J. Phys. Chem. A 2016, 120, 621-630. 
Graphical TOC Entry

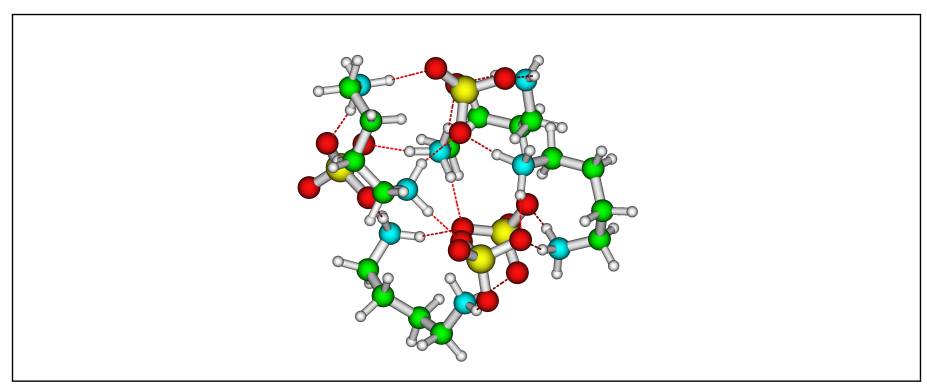

